\title{
Degradation kinetics of levoglucosan initiated by hydroxyl radical under different environmental conditions
}

\author{
Chengyue Lai, Yongchun Liu*, Jinzhu Ma, Qingxin Ma, Hong He* \\ Research Center for Eco-Environmental Sciences, Chinese Academy of Sciences, Beijing 100085, China
}

\section{H I G H L I G H T S}

- Mixing state significantly slows down the reactivity of levoglucosan toward $\mathrm{OH}$.

- Low RH and high temperature are favorable to degradation of levoglucosan.

- Degradation of levoglucosan should be prominent in the atmosphere.

\section{A R T I C L E I N F O}

\section{Article history:}

Received 21 October 2013

Received in revised form

21 March 2014

Accepted 25 March 2014

Available online 25 March 2014

\section{Keywords:}

Levoglucosan

Hydroxyl radical

Degradation kinetics

Environmental condition

Mixing state

\begin{abstract}
A B S T R A C T
To understand the atmospheric stability of levoglucosan, which is a major molecular tracer used for source apportionment of biomass burning aerosols, degradation kinetics of levoglucosan by hydroxyl radical $(\mathrm{OH})$ have been investigated using a flow reactor under different conditions. The second-order rate constant $\left(k_{2}\right)$ for the degradation of pure levoglucosan by $\mathrm{OH}$ is $(9.17 \pm 1.16) \times 10^{-12} \mathrm{~cm}^{3}$ molecules ${ }^{-1} \mathrm{~s}^{-1}$ at $25^{\circ} \mathrm{C}$ and $40 \%$ relative humidity $(\mathrm{RH})$, while it depends on environmental conditions such as temperature, $\mathrm{RH}$, and mixing state. At $25{ }^{\circ} \mathrm{C}, k_{2}$ of pure levoglucosan linearly decreases with increasing $\mathrm{RH}$ $\left(k_{2}=(1.50 \pm 0.04) \times 10^{-11}-(1.31 \pm 0.11) \times 10^{-11} R H\right)$, while it increases with increasing temperature and follows the Arrhenius equation $k_{2}=(6.2 \pm 5.6) \times 10^{-9} \exp [(-1922.5 \pm 268.2) / T]$ when the RH is $40 \%$. At $25{ }^{\circ} \mathrm{C}$ and $40 \% \mathrm{RH}$, compared to pure levoglucosan, levoglucosan coated on $\left(\mathrm{NH}_{4}\right)_{2} \mathrm{SO}_{4}$ or $\mathrm{NaCl}$ (levoglucosan@( $\left.\mathrm{NH}_{4}\right)_{2} \mathrm{SO}_{4}$ and levoglucosan@NaCl) shows larger $k_{2}$ to $\mathrm{OH}$ with $(9.53 \pm 0.39) \times 10^{-12}$ and $(10.3 \pm 0.45) \times 10^{-12} \mathrm{~cm}^{3}$ molecules ${ }^{-1} \mathrm{~s}^{-1}$, respectively, whereas levoglucosan coated on soot (levoglucosan@soot) shows the smaller $k_{2}$ of $(4.04 \pm 0.29) \times 10^{-12} \mathrm{~cm}^{3}$ molecules ${ }^{-1} \mathrm{~s}^{-1}$. Either $\left(\mathrm{NH}_{4}\right)_{2} \mathrm{SO}_{4}$ or $\mathrm{NaCl}$ internally mixed with levoglucosan $\left(\left(\mathrm{NH}_{4}\right)_{2} \mathrm{SO}_{4} @\right.$ levoglucosan and $\mathrm{NaCl} @$ levoglucosan) prominently inhibits the degradation of levoglucosan. Based on the rate constants, atmospheric lifetimes of levoglucosan were estimated to be 1.2-3.9 days under different conditions. All the results indicate that the degradation of levoglucosan by $\mathrm{OH}$ is prominent during air mass aging, and it should have an important influence on the uncertainty of source apportionment if the contribution of degradation to levoglucosan concentration is not considered in source apportionment models.
\end{abstract}

(C) 2014 Elsevier Ltd. All rights reserved.

\section{Introduction}

Submicron particles can affect the radiation budget of earth, and also cause adverse health effects on human beings under high concentrations (Vermote et al., 2009; Yttri et al., 2009). In order to develop effective control strategies, it is critical to understand which sources contribute to their total mass (Chow and Watson, 2002; Saarnio et al., 2010). Source apportionment techniques, such as chemical mass balance (CMB) (Stone et al., 2008, 2010) and

\footnotetext{
* Corresponding authors.

E-mail addresses: ycliu@rcees.ac.cn (Y. Liu), honghe@rcees.ac.cn (H. He).
}

positive matrix factorization (PMF) (Healy et al., 2010; Lanz et al., 2007), have been developed and widely used for source apportionment. In both CMB and PMF models, concentrations of tracers for different sources are necessary as input parameters. In early studies, metal elements were widely used as tracers in source apportionment. However, organic tracers have become more and more commonly used recently due to the fact that they are more specific than metal elements in pollutant sources (Lin et al., 2010).

Biomass burning is one of the main source for atmospheric aerosols on the global scale, which has strong influence on the atmospheric aerosol composition. Levoglucosan (1,6-Anhydro- $\beta$-Dglucopyranose) is a specific component of particles emitted through biomass burning, and has recently been widely used as a 
molecular tracer in source apportionment (Engling et al., 2006; Mochida et al., 2010; Simoneit and Elias, 2001). A basic assumption in source apportionment models is that the tracers are stable in the atmosphere. Levoglucosan was thought to be stable enough in the past (Schauer et al., 1996), but a few recent studies have indicated that levoglucosan shows high reactivity to oxidizing radicals. For instance, using a smog chamber, Hennigan et al. (2010) found that levoglucosan can degrade quickly by $\mathrm{OH}$ radicals, with an atmospheric lifetime of 0.7-2.2 days. Using a flow reactor, Kessler et al. (2010) studied the heterogeneous oxidation of pure levoglucosan, with the second-order rate constant to be $(3.09 \pm 0.18) \times 10^{-13} \mathrm{~cm}^{3}$ molecules ${ }^{-1} \mathrm{~s}^{-1}$. Slade and Knopf (2013) investigated the uptake coefficients of $\mathrm{OH}$ by levoglucosan and some other biomass burning organic aerosol surrogate compounds, and identified the volatilized products and volatilization mechanisms. Shiraiwa et al. (2012) studied the reactions between levoglucosan and $\mathrm{NO}_{3}$ radicals and showed levoglucosan can be stable for just one week during $\mathrm{NO}_{3}$ aging. On regional scale, Mochida et al. (2010) observed a significant decay of levoglucosan in summer after long range transport. Using the SPACCIM model, Hoffmann et al. (2010) also concluded that the lifetime of levoglucosan is $12.7-33.1 \mathrm{~h}$ in summer and $72.8-83.2 \mathrm{~h}$ in winter due to the oxidation of levoglucosan by $\mathrm{OH}$ radicals in aqueous phases. The shorter lifetime of levoglucosan compared to the residence time of aerosols means atmospheric degradation should have an important influence on its measured concentration, and subsequently on the source strengths estimated by apportionment models.

When exposed to $\mathrm{OH}$, hydrogen abstraction should be the sole reaction pathway between $\mathrm{OH}$ and levoglucosan. Theoretical calculations showed the reactant complex $(\mathrm{OH}-\mathrm{OC})$ should be formed firstly before hydrogen abstraction occurs when organic compounds react with $\mathrm{OH}$ (Iuga et al., 2012). Levoglucosan is a polyhydroxy compound, thus it can easily interact with water through hydrogen bond. Therefore, it is reasonable to postulate that $\mathrm{H}_{2} \mathrm{O}$ might affect the formation of levoglucosan-OH complex. Accordingly, the reactivity of levoglucosan to $\mathrm{OH}$ may be dependent on the reaction relative humidity ( $\mathrm{RH}$, which usually varies from $20 \%$ to $90 \%$ in the atmosphere). Furthermore, the tropospheric temperature varies notably with the changing seasons, and some studies have already found that temperature will affect the reactions between different organic compounds and $\mathrm{OH}$ radicals (Lee et al., 2003; Perry et al., 1977). Therefore, it is significant to investigate the effect of relative humidity and temperature on the reaction between levoglucosan and $\mathrm{OH}$ radicals to evaluate the atmospheric lifetime of levoglucosan. To our knowledge, previous laboratory studies have not systematically considered the effect of these environmental factors on levoglucosan degradation by $\mathrm{OH}$ radicals.

In the real atmosphere, organic compounds always mix with other particulate matters during transport, thus their reactivity to oxidants can be modified. For instance, the uptake coefficient of $\mathrm{N}_{2} \mathrm{O}_{5}$ on mixtures of humic acid and $\left(\mathrm{NH}_{4}\right)_{2} \mathrm{SO}_{4}$ decreases more than a factor of two compared with the case for single-component $\left(\mathrm{NH}_{4}\right)_{2} \mathrm{SO}_{4}$ (Badger et al., 2006). The heterogeneous reactivity of benzo[a]pyrene ( $\mathrm{BaP}$ ) toward $\mathrm{O}_{3}$ was reduced substantially by a thin $(4-8 \mathrm{~nm})$, solid eicosane coating and entirely suppressed by thick (10-80 nm) solid eicosane coatings (Zhou et al., 2012). During biomass burning, a number of air pollutants will be generated, and soot may be the most significant one (Kozinski and Saade, 1998). Sodium chloride, as the principal component of sea salt, as well as secondary $\left(\mathrm{NH}_{4}\right)_{2} \mathrm{SO}_{4}$, are significant fractions of the total atmospheric particulate mass (Weis and Ewing, 1999). These particles are all likely to mix with levoglucosan in the real atmosphere. At the present time, however, it is as yet unknown how the mixing state with such particles will influence the stability of levoglucosan.
In this study, the degradation kinetics of levoglucosan exposed to $\mathrm{OH}$ radicals under different environmental conditions has been studied using a flow reactor. The aim of this work is to determine the degradation kinetic parameters and atmospheric lifetimes of levoglucosan under different relative humidity, different temperature, and in different mixing states with $\left(\mathrm{NH}_{4}\right)_{2} \mathrm{SO}_{4}, \mathrm{NaCl}$ and soot. The results obtained from this work will update the understanding of the fate of levoglucosan in the atmosphere.

\section{Experimental}

\subsection{Reaction procedure and analytical methods}

The set-up utilized in this study is shown in Fig. S1. All the experiments were performed using a flow system with a stainless steel reactor. The interior walls were coated with Teflon to provide a chemically inert surface. The volume of the reactor is $30 \mathrm{~cm}^{3}$. A Teflon disc (geometric surface area $3.39 \mathrm{~cm}^{2}$ ) was used as sample holder. For the kinetic studies, $(0.50 \pm 0.01) \mu \mathrm{g}$ of solid levoglucosan film on the disc was evenly generated by gently drying levoglucosan $/ \mathrm{CH}_{3} \mathrm{CN}$ solution (Saarnio et al., 2010). In the case of reactions for the mixed samples, $(100.0 \pm 0.1) \mathrm{mg}$ of each sample was evenly deposited on the disc. The reactor was purged with simulated air (80\% high purity $\mathrm{N}_{2}$ and $20 \%$ high purity $\mathrm{O}_{2}$ ) and bubbled $\mathrm{H}_{2} \mathrm{O}_{2}$ flow. The $\mathrm{RH}$ of the system was controlled by varying the ratio of wet $\mathrm{N}_{2}$ flow, which is achieved by bubbling $\mathrm{H}_{2} \mathrm{O}$ with nitrogen, to dry $\mathrm{N}_{2}$ flow. The total flow rate is kept at $500 \mathrm{~mL} \mathrm{~min}^{-1}$. RH was determined by a humidity temperature meter (CENTER314 ) at the exit of the reactor with an uncertainty less than $3 \% \mathrm{RH}$. Temperature of the system was controlled by a circulating water bath (CCA-20, Gongyi City YUHUA Instrument Co., Ltd) and can be accurately adjusted with an uncertainty of less than $0.5{ }^{\circ} \mathrm{C}$. The water partial pressure in the system may change while the temperature changes, but a constant $\mathrm{RH}$ was kept at different temperatures by adjusting the ratio of wet $\mathrm{N}_{2}$ flow to dry $\mathrm{N}_{2}$ flow in this study.

The reacted samples were ultrasonically extracted using $(20.0 \pm 0.1) \mathrm{mL} \mathrm{CH}_{3} \mathrm{CN}$ and then filtered using a glass fiber filter which had been previously cleaned by ultrasonication in $\mathrm{CH}_{3} \mathrm{CN}$. Subsequently, the eluate was evaporated to nearly dryness, transferred into a $1.5 \mathrm{~mL}$ graduated vial and then dried under a gentle nitrogen stream.

The high polarity of levoglucosan demands a derivatization step prior to GC analysis. In this study, N,O-bis-(trimethylsilyl)trifluoroacetamide (BSTFA) plus 1\% trimethylchlorosilane (TMCS) was used as silylation reagent for the derivatization of levoglucosan (Pietrogrande et al., 2010). $50 \mu \mathrm{L}$ of BSTFA plus $1 \%$ TMCS and $50 \mu \mathrm{L}$ of pyridine was added to the residue from previous steps, and the silylation reaction was performed at $333 \mathrm{~K}$ for $60 \mathrm{~min}$. Then $1.0 \mu \mathrm{L}$ of the silylation product was injected into the GC-MS system. Detailed GC-MS parameters and procedures are shown in the Supporting information.

\subsection{OH generation and detection}

$\mathrm{OH}$ radicals were generated in a quartz chamber by the UV photolysis of $\mathrm{H}_{2} \mathrm{O}_{2}$. Two ultraviolet light lamps (18 W, Beijing Lighting Research Institute) which provided UV-radiation with a central wavelength around $254 \mathrm{~nm}$ were used. The concentration of $\mathrm{OH}$ radical was controlled by varying the ratio of pure $\mathrm{N}_{2}$ and $\mathrm{H}_{2} \mathrm{O}_{2}$ flow passing through the lamp.

Salicylic acid has strong reactivity with $\mathrm{OH}$ radical, and is commonly used to trap OH radicals (Chiueh et al., 1992). Detailed descriptions of the rationality for using salicylic acid as the reference compound to detect $\mathrm{OH}$ concentration in this study and the 
experimental procedures were shown in the Supporting information. Briefly, salicylic acid and levoglucosan show similar morphology and particle size. Furthermore, the near-surface $\mathrm{OH}$ concentration will depend on the substrate reactivity to $\mathrm{OH}$. However, as analyzed in the Supporting information, the secondorder rate constant $\left(k_{2}\right)$ of salicylic acid is very close to the measured $k_{2}$ of levoglucosan. Therefore, it is reasonable to use salicylic acid as a reference compound in this work.

In this study, the decay rate of salicylic acid when reacted with $\mathrm{OH}$ radical and the yield rate of the products (2,3-dihydroxybenzonic acid and 2,5-dihydroxybenzonic acid) for the reactions between salicylic acid and $\mathrm{OH}$ were both used to estimate the near-surface gas phase concentration of $\mathrm{OH}$ radicals before the levoglucosan degradation experiments were carried out. The results showed comparable near-surface gas phase $\mathrm{OH}$ concentrations between two methods. In the subsequent experiments, the near-surface gas phase $\mathrm{OH}$ concentrations were controlled approximately from $7 \times 10^{6}$ molecules $\mathrm{cm}^{-3}$ to $5 \times 10^{7}$ molecules $\mathrm{cm}^{-3}$.

\subsection{Mixed sample preparation and characterization}

In this paper, a symbol $\mathrm{A} @ \mathrm{~B}$ is defined to represent $\mathrm{A}$ coated on $B$. To simulate different mixing states, levoglucosan was coated on $\left(\mathrm{NH}_{4}\right)_{2} \mathrm{SO}_{4}, \mathrm{NaCl}$ and soot particles (corresponding to levoglucosan@( $\left.\mathrm{NH}_{4}\right)_{2} \mathrm{SO}_{4}$, levoglucosan@NaCl and levoglucosan@soot), internally mixed with $\left(\mathrm{NH}_{4}\right)_{2} \mathrm{SO}_{4}$ and $\mathrm{NaCl}$ (corresponding to $\left(\mathrm{NH}_{4}\right)_{2} \mathrm{SO}_{4} @$ levoglucosan and $\mathrm{NaCl} @$ levoglucosan), and also mixed with both soot and $\left(\mathrm{NH}_{4}\right)_{2} \mathrm{SO}_{4}$ (corresponding to $\left(\mathrm{NH}_{4}\right)_{2} \mathrm{SO}_{4} @ l e v o-$ glucosan@soot). Before mixed with levoglucosan, the inorganics were all cleaned by ultrasonication in $\mathrm{CH}_{3} \mathrm{CN}$, followed by drying at room temperature. Soot particles were further preheated at $300{ }^{\circ} \mathrm{C}$ under $\mathrm{N}_{2}$ protection for $8 \mathrm{~h}$.

Levoglucosan was mixed with the inorganics through an impregnation method (Ma et al., 2010a). Detailed preparation procedures for the mixed samples were shown in the Supporting information. All the mixed samples were dried at room temperature and stored at $-18{ }^{\circ} \mathrm{C}$ in the dark. To keep a unified initial concentration of levoglucosan, equivalently $5.0 \mu \mathrm{g}$ of levoglucosan was used for each experiment.

To understand the mixing state and particle size, Scanning Electron Microscope (SEM, Hitachi SU8000 with an accelerating voltage of $10 \mathrm{kV}$ ) was conducted for the mixed samples levoglucosan@NaCl, levoglucosan@( $\left.\mathrm{NH}_{4}\right)_{2} \mathrm{SO}_{4}, \quad \mathrm{NaCl} @ l e v o g l u c o s a n$, $\left(\mathrm{NH}_{4}\right)_{2} \mathrm{SO}_{4} @$ levoglucosan and Transmission Electron Microscope (TEM, Hitachi $\mathrm{H}-7500$ with an acceleration voltage of $80 \mathrm{kV}$ ) was used for levoglucosan@soot, $\left(\mathrm{NH}_{4}\right)_{2} \mathrm{SO}_{4} @ l$ levoglucosan@soot. The measured particle size of the mixed samples varies from $66 \pm 10.1$ to $404 \pm 67.7 \mathrm{~nm}$ (shown in Table S1). Furthermore, in order to understand the surface state of the mixed samples, Scanning Electron Microscopy with X-ray microanalysis (SEM-EDX, Hitachi SU8000 with an accelerating voltage of $30 \mathrm{kV}$ ) were also used to detect the element composition on the surface of each sample.

\subsection{Chemicals}

All chemicals were of chromatographic grade and used as received. Acetonitrile was obtained from Fisher Scientific. Standard of levoglucosan was purchased from AccuStandard, Inc. N,O-bis(trimethylsilyl)trifluoroacetamide plus trimethylchlorosilane (BSTFA:TMCS = 99:1) and salicylic acid (>99.5\%) were purchased from Tokyo Chemical Industry Co., Ltd. Pyridine, $\mathrm{NaCl},\left(\mathrm{NH}_{4}\right)_{2} \mathrm{SO}_{4}$ and $30 \% \mathrm{H}_{2} \mathrm{O}_{2}$ were purchased from Sinopharm Chemical Reagent Co., Ltd. Printex U powder from Degussa (CAS No.: 1333-86-4) was used as a model soot aerosol in this study. Its specific surface area was $97.24 \mathrm{~m}^{2} \mathrm{~g}^{-1}$, measured using nitrogen Brunauer-EmmettTeller (BET) physisorption (Quantachrome Autosorb-1-C). High purity $\mathrm{N}_{2}$ (99.99\%) and $\mathrm{O}_{2}$ (99.99\%) were supplied by Beijing AP BEIFEN Gases Inc.

\section{Results and discussion}

\subsection{Feasibility of the test system}

In order to evaluate the influence of vaporization and degradation by $\mathrm{H}_{2} \mathrm{O}_{2}$ on levoglucosan, blank experiments were performed under the same conditions as those used for the oxidation reactions with air flow and $\mathrm{H}_{2} \mathrm{O}_{2}$ flow, respectively. The experiments were carried out at $40 \% \mathrm{RH}$ with a temperature range from $5{ }^{\circ} \mathrm{C}$ to $35^{\circ} \mathrm{C}$ in the dark. As shown in Fig. S5, the vaporization of levoglucosan and degradation by $\mathrm{H}_{2} \mathrm{O}_{2}$ were less than $10 \%$ under different temperatures. This has been considered for kinetics calculations in the following section.

To test the accuracy of the experimental data acquired from the flow reaction system used in this study, different $\mathrm{OH}$ concentrations (near-surface gas phase concentration, similarly hereinafter) were achieved and the reactions with levoglucosan were carried out. Four different $\mathrm{OH}$ concentrations were adjusted and estimated by salicylic acid previously in this study. They were approximately $7.7 \times 10^{6}$ molecules $\mathrm{cm}^{-3}, 1.9 \times 10^{7}$ molecules $\mathrm{cm}^{-3}$, $3.5 \times 10^{7}$ molecules $\mathrm{cm}^{-3}$ and $5.3 \times 10^{7}$ molecules $\mathrm{cm}^{-3}$, respectively. The kinetic data were determined by monitoring the loss of levoglucosan concentration as a function of $\mathrm{OH}$ exposure time at $25{ }^{\circ} \mathrm{C}$ with $40 \% \mathrm{RH}$ in the dark. As shown in Fig. 1, degradation of levoglucosan was prominent under different $\mathrm{OH}$ concentrations and exhibited an exponential behavior. Therefore, the reactions can be reasonably described by pseudo-first-order kinetics, and the experimental data can be fitted using pseudo-first-order exponential functions. The method for calculating $k_{1}$ was similar to the study carried out by Ma et al. (2010a), and the pseudo-first-order exponential function was as follows,

$\frac{[\mathrm{LEV}]_{t}}{[\mathrm{LEV}]_{0}}=\frac{[\mathrm{LEV}]_{\text {plateau }}}{[\mathrm{LEV}]_{0}}+\frac{[\mathrm{LEV}]_{0}-[\mathrm{LEV}]_{\text {plateau }}}{[\mathrm{LEV}]_{0}} \times \exp \left(-k_{1} \times t\right)$

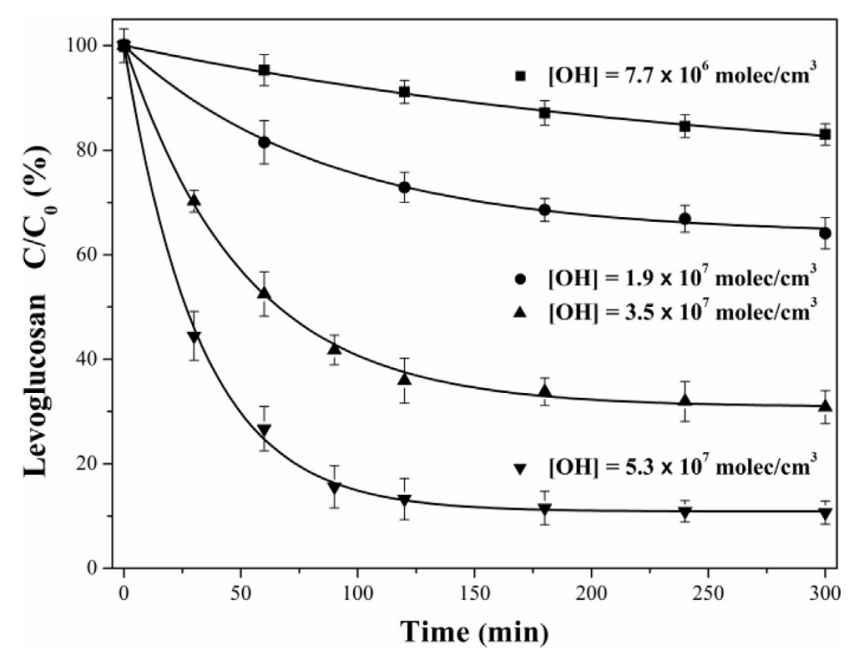

Fig. 1. Representative levoglucosan decays observed under four different near-surface gas phase $\mathrm{OH}$ concentrations at $25{ }^{\circ} \mathrm{C}$ and $40 \% \mathrm{RH}(n=3$, error bars represent 1 standard deviation of the triplicate analysis performed every time). 
where $[\mathrm{LEV}]_{t}$ is the concentration of levoglucosan at a given time, $[\mathrm{LEV}]_{0}$ is the initial concentration of levoglucosan, [LEV $]_{\text {plateau }}$ is the concentration of levoglucosan at the plateau, and $k_{1}$ is the apparent rate constant of the pseudo-first-order reaction.

The second-order rate constants were $\left(k_{2}\right)$ calculated through $k_{2}=k_{1} /[\mathrm{OH}]$, where $[\mathrm{OH}]$ was the near-surface gas phase $\mathrm{OH}$ concentration, and are listed in Table 1. Generally, if the heterogeneous reaction experiments are carried out under ambient pressure and on packed powder samples, both external (gaseous reactants from gas phase to the surface) and internal diffusions (from the surface layer to the underneath layers and into the pores of particles or films) need be corrected (Keyser et al., 1991; Underwood et al., 2001; Widmann and Davis, 1997). However, as discussed detailedly in the Supporting information, it is unnecessary to do both external and internal diffusion corrections because the following reasons. Firstly, the near-surface but not gas phase $\mathrm{OH}$ concentrations were measured with a particle phase reference. Secondly, all the samples are nonporous with smooth surfaces as supported by SEM results. Finally, the reactions between $\mathrm{OH}$ and organic compounds are limited on the surface (George and Abbatt, 2010).

From Table 1, it can be seen that the values of second-order rate constants were similar when the concentrations of $\mathrm{OH}$ radicals were higher than $1.9 \times 10^{7}$ molecules $\mathrm{cm}^{-3}$, indicating that the results from the setup were stable and repeatable.

The second-order rate constant for the levoglucosan- $\mathrm{OH}$ reaction was determined to be $(1.1 \pm 0.5) \times 10^{-11} \mathrm{~cm}^{3}$ molecules ${ }^{-1} \mathrm{~s}^{-1}$ in a previous chamber experiment carried out by Hennigan et al. (2010) and $(3.09 \pm 0.18) \times 10^{-13} \mathrm{~cm}^{3}$ molecules ${ }^{-1} \mathrm{~s}^{-1}$ using a flow reactor by Kessler et al. (2010), respectively. Meanwhile, the rate constant was estimated to be $5.28 \times 10^{-11} \mathrm{~cm}^{3}$ molecules ${ }^{-1} \mathrm{~s}^{-1}$ by the Atmospheric Oxidation Program for Microsoft Windows
(AOPWIN) model based on structure-activity relationship (QSAR) (Meylan and Howard, 1993) and $2.21 \times 10^{-13} \mathrm{~cm}^{3}$ molecules ${ }^{-1} \mathrm{~s}^{-1}$ through quantum chemical calculations (Bai et al., 2013). In this study, the average rate constant for the levoglucosan-OH reaction was determined to be $(9.17 \pm 1.16) \times 10^{-12} \mathrm{~cm}^{3}$ molecules ${ }^{-1} \mathrm{~s}^{-1}$, which shows good agreement with the chamber experiment results, but is obviously below the result obtained through QSAR calculation and much higher than the quantum chemical calculations and the flow reactor experiment results. The disagreement of the data obtained in this study and the calculation results may probably due to the uncertainties of such calculations. The inconsistent results between the results obtained in this study and the flow reactor experiment results by Kessler et al. (2010) may be because in their study, the concentration of levoglucosan was detected by aerosol mass spectrometer (AMS). The interference of the reaction product cannot be eliminated if non-molecular ions were used to detect levoglucosan, thus significantly reduce the $k_{2}$ value. Moreover, it should be pointed out that in Kessler et al.'s work, $\mathrm{OH}$ concentration is much higher than that in this study, so the different results might also due to the different region of $\mathrm{OH}$ concentration.

\subsection{Effect of different environmental conditions}

To investigate the effect of different environmental conditions, the relative humidity $(\mathrm{RH})$ of the reaction system was adjusted to approximately $20 \%, 40 \%, 60 \%$, and $80 \%$ under a fixed temperature of $25^{\circ} \mathrm{C}$ for the relative humidity effect research, and the temperature of the system was regulated to $5{ }^{\circ} \mathrm{C}, 15^{\circ} \mathrm{C}, 25^{\circ} \mathrm{C}$ and $35^{\circ} \mathrm{C}$ under a constant relative humidity of $40 \%$ for the temperature effect studies. In this part, the concentration of $\mathrm{OH}$ radical was adjusted to approximately $3.5 \times 10^{7}$ molecules $\mathrm{cm}^{-3}$ and all the experiments

Table 1

Calculated rate constant and atmospheric lifetimes of levoglucosan for the reaction between levoglucosan and OH radicals under different atmospheric conditions.

\begin{tabular}{|c|c|c|c|c|}
\hline \multicolumn{3}{|l|}{ Reaction conditions } & \multirow{2}{*}{ 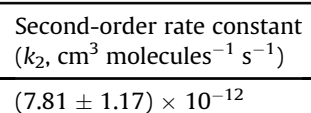 } & \multirow{2}{*}{$\begin{array}{l}\text { Atmospheric lifetime (days) } \\
-\end{array}$} \\
\hline Pure levoglucosan & \multicolumn{2}{|c|}{$[\mathrm{OH}]=7.7 \times 10^{6}$ molecule $\mathrm{cm}^{-3}$} & & \\
\hline & \multicolumn{2}{|c|}{$[\mathrm{OH}]=1.9 \times 10^{7}$ molecule $\mathrm{cm}^{-3}$} & $(9.80 \pm 0.69) \times 10^{-12}$ & 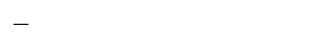 \\
\hline & \multicolumn{2}{|c|}{$[\mathrm{OH}]=3.5 \times 10^{7}$ molecule $\mathrm{cm}^{-3}$} & $(9.25 \pm 0.32) \times 10^{-12}$ & - \\
\hline & \multicolumn{2}{|c|}{$[\mathrm{OH}]=5.3 \times 10^{7}$ molecule $\mathrm{cm}^{-3}$} & $(9.84 \pm 0.29) \times 10^{-12}$ & - \\
\hline & \multicolumn{2}{|l|}{ Average $^{\mathrm{b}}$} & $(9.17 \pm 1.16) \times 10^{-12}$ & $1.7 \pm 0.5$ \\
\hline & \multicolumn{2}{|c|}{$\begin{array}{l}\text { Chamber experiment by Hennigan et al. } \\
\text { (2010) }\end{array}$} & $(1.1 \pm 0.5) \times 10^{-11}$ & $1.3 \pm 0.3$ \\
\hline & \multicolumn{2}{|c|}{$\begin{array}{l}\text { Flow reactor experiment by Kessler et al. } \\
\text { (2010) }\end{array}$} & $(3.09 \pm 0.18) \times 10^{-13}$ & $21 \pm 0.5$ \\
\hline & \multicolumn{2}{|c|}{$\begin{array}{l}\text { AOPWIN model by Meylan and Howard } \\
\text { (1993) }\end{array}$} & $5.28 \times 10^{-11}$ & 0.4 \\
\hline & \multicolumn{2}{|c|}{$\begin{array}{l}\text { Quantum chemical calculations by Bai } \\
\text { et al. (2013) }\end{array}$} & $2.21 \times 10^{-13}$ & 26 \\
\hline & \multirow[t]{4}{*}{$\mathrm{RH}$ effect ${ }^{\mathrm{c}}$} & $20 \%$ & $(12.5 \pm 0.17) \times 10^{-12}$ & $1.2 \pm 0.1$ \\
\hline & & $40 \%$ & $(9.07 \pm 0.30) \times 10^{-12}$ & $1.7 \pm 0.1$ \\
\hline & & $60 \%$ & $(7.29 \pm 0.34) \times 10^{-12}$ & $2.1 \pm 0.1$ \\
\hline & & $80 \%$ & $(4.73 \pm 0.38) \times 10^{-12}$ & $3.3 \pm 0.3$ \\
\hline & \multirow[t]{4}{*}{ Temperature effect ${ }^{\mathrm{d}}$} & $5{ }^{\circ} \mathrm{C}$ & $(6.33 \pm 0.16) \times 10^{-12}$ & $2.4 \pm 0.1$ \\
\hline & & $15^{\circ} \mathrm{C}$ & $(7.18 \pm 0.44) \times 10^{-12}$ & $2.2 \pm 0.1$ \\
\hline & & $25^{\circ} \mathrm{C}$ & $(9.07 \pm 0.30) \times 10^{-12}$ & $1.7 \pm 0.1$ \\
\hline & & $35^{\circ} \mathrm{C}$ & $(12.1 \pm 0.72) \times 10^{-12}$ & $1.3 \pm 0.1$ \\
\hline \multirow[t]{6}{*}{ Mixed sample $e^{e}$} & \multicolumn{2}{|c|}{ levoglucosan@( $\left.\mathrm{NH}_{4}\right)_{2} \mathrm{SO}_{4}$} & $(9.53 \pm 0.39) \times 10^{-12}$ & $1.6 \pm 0.1$ \\
\hline & \multicolumn{2}{|c|}{$\left(\mathrm{NH}_{4}\right)_{2} \mathrm{SO}_{4} @$ levoglucosan } & $(7.17 \pm 0.18) \times 10^{-12}$ & $2.1 \pm 0.1$ \\
\hline & \multicolumn{2}{|c|}{ levoglucosan@NaCl } & $(10.3 \pm 0.45) \times 10^{-12}$ & $1.5 \pm 0.1$ \\
\hline & \multicolumn{2}{|l|}{ NaCl@levoglucosan } & $(6.15 \pm 0.34) \times 10^{-12}$ & $2.5 \pm 0.1$ \\
\hline & \multicolumn{2}{|l|}{ levoglucosan@soot } & $(4.04 \pm 0.29) \times 10^{-12}$ & $3.8 \pm 0.3$ \\
\hline & \multicolumn{2}{|c|}{$\left(\mathrm{NH}_{4}\right)_{2} \mathrm{SO}_{4} @ l e v o g l u c o s a n @ s o o t$} & $(3.97 \pm 0.99) \times 10^{-12}$ & $3.9 \pm 0.8$ \\
\hline
\end{tabular}

\footnotetext{
assuming the typical concentration for $12 \mathrm{~h}$ average value of $\mathrm{OH}$ to be $1.5 \times 10^{6}$ molecules $\mathrm{cm}^{-3}$.

b Experimental condition: $\mathrm{RH}=40 \%$, Temperature $=25^{\circ} \mathrm{C}$.

c Experimental condition: $[\mathrm{OH}]=3.5 \times 10^{7}$ molecules $\mathrm{cm}^{-3}$, Temperature $=25^{\circ} \mathrm{C}$.

d Experimental condition: $[\mathrm{OH}]=3.5 \times 10^{7}$ molecules $\mathrm{cm}^{-3}, \mathrm{RH}=40 \%$.

e Experimental condition: $[\mathrm{OH}]=3.5 \times 10^{7}$ molecules $\mathrm{cm}^{-3}, \mathrm{RH}=40 \%$, Temperature $=25^{\circ} \mathrm{C}$.
} 

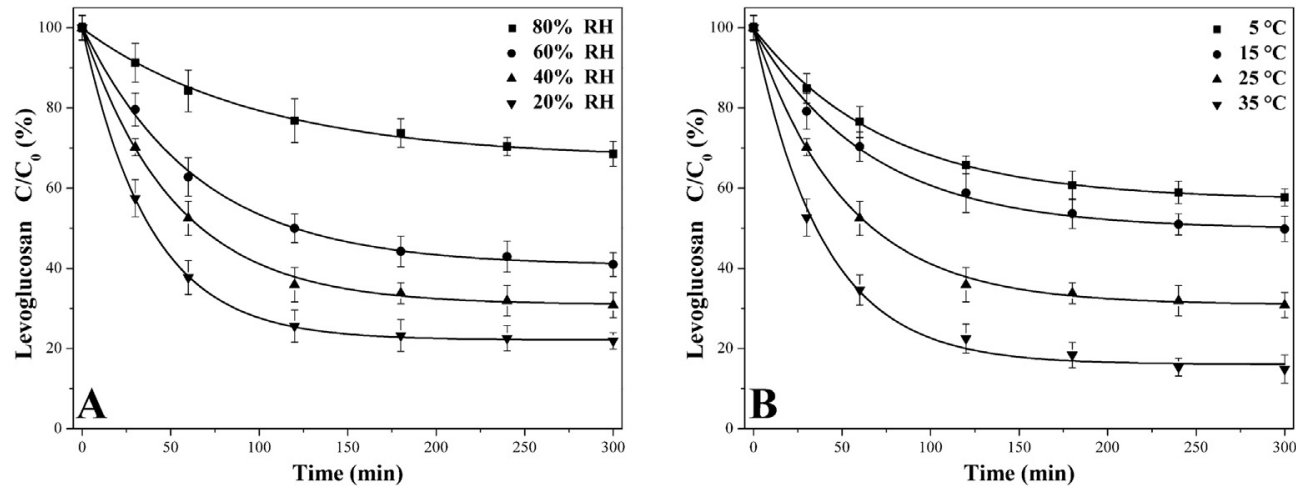

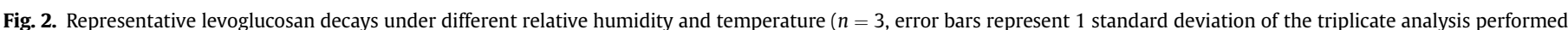

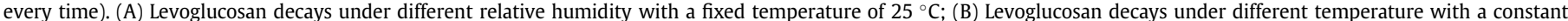
relative humidity of $40 \%$.

were conducted in the dark. The results are shown in Fig. 2. The pseudo-first-order rate constants of the reactions were calculated through Equation (1), and second-order rate constants for each reaction are listed in Table 1.

The results show that the degradation of levoglucosan was significantly influenced by both relative humidity and temperature. Levoglucosan degraded faster under low relative humidity when temperature was fixed (Fig. 2A), the second-order rate constant linearly decreases with increasing relative humidity, namely $k_{2}=(1.50 \pm 0.04) \times 10^{-11}-(1.31 \pm 0.11) \times 10^{-11} R H$ in units of $\mathrm{cm}^{3}$ molecules ${ }^{-1} \mathrm{~s}^{-1}(r=0.9803)$. Meanwhile, from Fig. 2B, it can be seen that high temperature leads to faster levoglucosan decay.

Absorbed water may affect the reactivity of levoglucosan to $\mathrm{OH}$ in two ways. Firstly, under high RH, water may decrease the viscosity of particles or film and dissolves the reactants which will promote the reaction (Shiraiwa et al., 2012, 2011). In this study, the water adsorption behavior of levoglucosan was measured using an AUTOSORB-1-C physisorption analyzer (Quantachrome, US). Detailed methodology for the analysis of water adsorption capacity has been described elsewhere (Ma et al., 2010b). From the data obtained from the physisorption analyzer (shown in Fig. 3), it was observed that there are only a few thin layers of physically adsorbed water on the surface of levoglucosan at low relative humidity; when the relative humidity increased to a critical value of

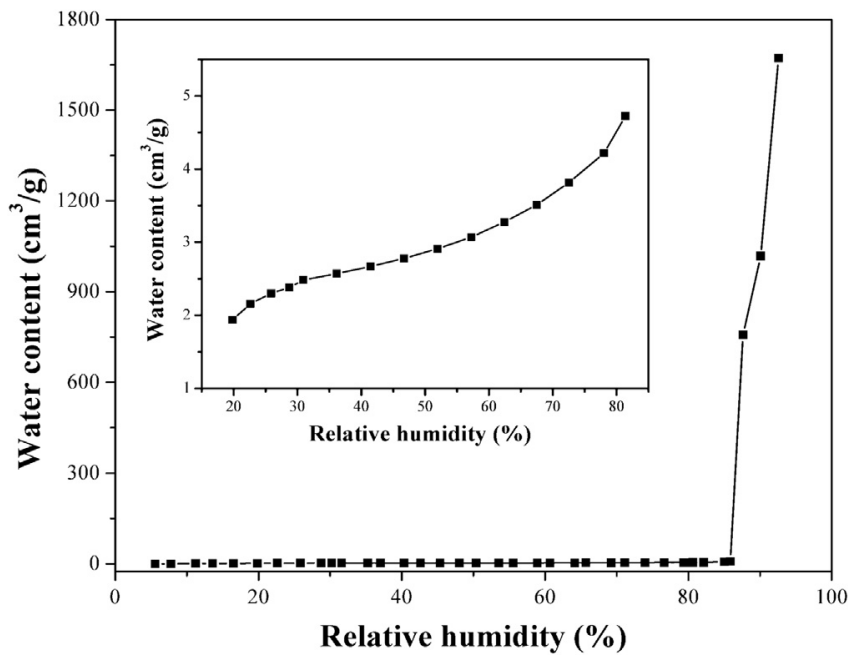

Fig. 3. Adsorption isotherms of water on $19.7 \mathrm{mg}$ levoglucosan. (The insert graph magnifies the adsorption isotherms of water on levoglucosan at RH $20-80 \%$.) approximately $85 \%$, the amount of absorbed water increased abruptly. The critical relative humidity was so-called deliquescence relative humidity (DRH). In the case of higher relative humidity (>85\%), as Hoffmann et al. described (Hoffmann et al., 2010), aqueous reaction may become the dominant pathway for the decay of levoglucosan. But in this study, due to the constraints of the setup, the experiments in such high RH cannot be carried out. In the range of $20-80 \% \mathrm{RH}$, a slow increase rate for water adsorption can be seen from the inset graph of Fig. 3. Two parameter BET equation was used to fit the isotherms of levoglucosan at $\mathrm{RH} 20-80 \%$, and the results show that the monolayer adsorption of water occurred at $21.6 \% \mathrm{RH}$ on levoglucosan. The mass of water adsorbed on levoglucosan was probably converted into coverage of about $1-2$ monolayers in the $\mathrm{RH}$ region $20-80 \%$. If adsorbed water is not enough to soften levoglucosan, water film covered on the surface might decrease the reactivity by decrease the diffusion of $\mathrm{OH}$. Therefore, the phase state may not be a prominent factor under the $\mathrm{RH}$ range studied in this work.

Secondly, water might also chemically influence the reactivity. According to Structure-Activity-Relationship (in gas-phase), the rate of hydrogen abstraction is $5.2 \times 10^{-11} \mathrm{~cm}^{3}$ molecules ${ }^{-1} \mathrm{~s}^{-1}$, while reaction rate between $\mathrm{OH}$ groups and $\mathrm{OH}$ radical is $4.2 \times 10^{-13} \mathrm{~cm}^{3}$ molecules ${ }^{-1} \mathrm{~s}^{-1}$. Detailed hydrogen abstraction calculation is shown in the Supporting information. Therefore, approximately $60 \%$ of reactivity stems from $\mathrm{HO}-\mathrm{C}-\mathrm{H}$ for hydrogen abstraction. The absorbed water on the $\mathrm{OH}$ group may increase the steric hindrance between $\mathrm{OH}$ radical and $\mathrm{HO}-\mathrm{C}-\mathrm{H}$ during the formation of transition state. This means the effect of water on heterogeneous reactivity of levoglucosan may depend on structure of itself. Certainly, it is noteworthy that the lower deliquescence relative humidity for levoglucosan aerosol particles may lead to different state of levoglucosan compared to the dry levoglucosan film used in this study, thus lead different reactivity to water, while the data obtained here can also give the information about the influence of $\mathrm{RH}$ in the degradation of levoglucosan by $\mathrm{OH}$.

Fig. 4 shows an Arrhenius plot of the measured rate constants for the reaction between levoglucosan and $\mathrm{OH}$. A positive temperature dependence was observed and the Arrhenius expression is calculated to be $k_{2}=(6.2 \pm 5.6) \times 10^{-9} \exp [(-1922.5 \pm 268.2) / T$ in units of $\mathrm{cm}^{3}$ molecules ${ }^{-1} \mathrm{~s}^{-1}$. High temperature may impel the gas/ particle partitioning occur (Ding et al., 2011), thus lead more gas phase levoglucosan in the reactor. May et al. (2012) also investigated the thermodynamic properties affect gas-particle partitioning (saturation concentration and enthalpy of vaporization) for eight organic tracers (including levoglucosan) under temperature range of $20-80^{\circ} \mathrm{C}$ and found that levoglucosan to be semivolatile 


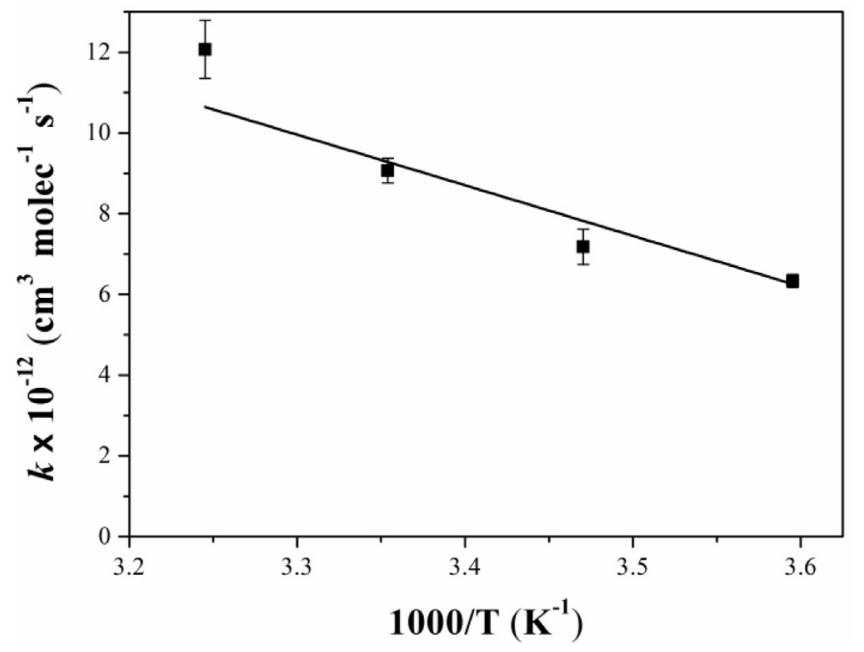

Fig. 4. Measured rate constants for the levoglucosan-OH reaction as a function of temperature.

under atmospheric conditions, which will increase the gas-particle partitioning along with the temperature increases, thus lead to accelerated chemical oxidation. However, the influence of evaporation on kinetics has been considered in this study. The melting point of levoglucosan is $455 \mathrm{~K}$, and is much higher than the highest temperature $(308 \mathrm{~K}$ ) in this study, so the narrow temperature range should have no influence on the phase state of levoglucosan film. The positive temperature dependence of the rate constant means that formation of transition state needs to be activated and the reactivity is promoted at higher temperature. In the ambient, this means degradation rate of levoglucosan should be faster in summer than in winter. Our results well explain the results obtained by
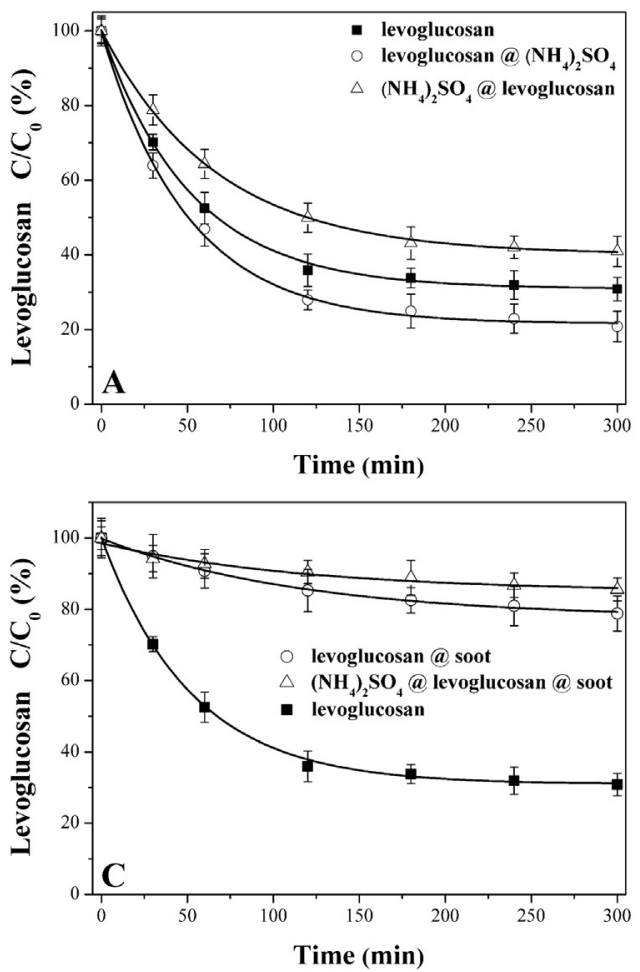

Hoffmann et al. that the lifetime of levoglucosan in summer is shorter than that in winter (Hoffmann et al., 2010).

\subsection{Effect of different mixing states}

In this study, levoglucosan was coated on $\left(\mathrm{NH}_{4}\right)_{2} \mathrm{SO}_{4}, \mathrm{NaCl}$ and soot particles, internally mixed with $\left(\mathrm{NH}_{4}\right)_{2} \mathrm{SO}_{4}$ and $\mathrm{NaCl}$, and also mixed with both soot and $\left(\mathrm{NH}_{4}\right)_{2} \mathrm{SO}_{4}$ to simulate different mixing states. The visual images of mixed samples were shown in Fig. S6, and the average sizes of the mixed samples were sub-micrometer and were listed in Table S1. From the data obtained, these crystals can be recognized as atmospherically relevant. Reactions for the mixed samples to $\mathrm{OH}$ were performed at $25^{\circ} \mathrm{C}$ and $40 \% \mathrm{RH}$. In this part, the concentration of $\mathrm{OH}$ radical was adjusted to approximately $3.5 \times 10^{7}$ molecules $\mathrm{cm}^{-3}$ and all the experiments were carried out in the dark. The results for the levoglucosan-OH reactions on the mixed samples are shown in Fig. 5. Table 1 shows the second-order rate constant for each reaction. The results indicate that the degradation of levoglucosan was significantly influenced by the mixing state. When coated on inorganic salts (corresponding to levoglucosan@NaCl and levoglucosan@ $\left.\left(\mathrm{NH}_{4}\right)_{2} \mathrm{SO}_{4}\right)$, there was a slight increase of the rate constants for the levoglucosan-OH reaction. While internally mixed with such inorganic salts (corresponding to $\mathrm{NaCl} @$ levoglucosan and $\left.\left(\mathrm{NH}_{4}\right)_{2} \mathrm{SO}_{4} @ l e v o g l u c o s a n\right)$, an obvious reduction of the rate constant was observed.

SEM-EDX results for levoglucosan mixed samples were shown in Table S2. Based on semi-quantitative analysis, the carbon content (wt) on the surface of levoglucosan@NaCl and levoglucosan@ $\left(\mathrm{NH}_{4}\right)_{2} \mathrm{SO}_{4}(35.31 \%$ and $18.84 \%)$ are higher than that on pure $\mathrm{NaCl}$ and $\left(\mathrm{NH}_{4}\right)_{2} \mathrm{SO}_{4}$ (3.08\% and 2.86\%), which confirms that levoglucosan was successfully coated on the surface of $\mathrm{NaCl}$ and $\left(\mathrm{NH}_{4}\right)_{2} \mathrm{SO}_{4}$. The higher dispersion degree for levoglucosan in levoglucosan@ $\mathrm{NaCl}$ and levoglucosan@( $\left.\mathrm{NH}_{4}\right)_{2} \mathrm{SO}_{4}$ than pure levoglucosan surfaces may lead to higher rate constants compared with

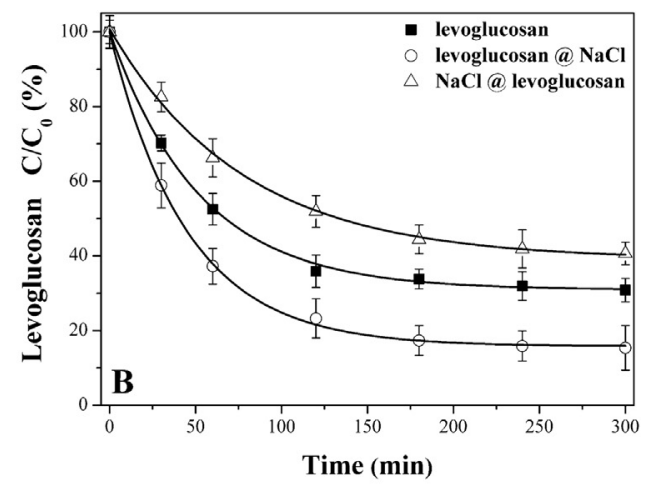

Time (min)

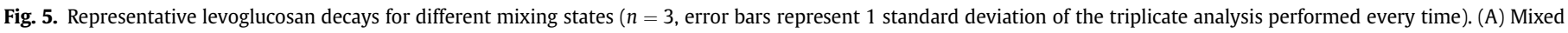
with $\left(\mathrm{NH}_{4}\right)_{2} \mathrm{SO}_{4}$. (B) Mixed with $\mathrm{NaCl}$. (C) Mixed with soot or both soot and $\left(\mathrm{NH}_{4}\right)_{2} \mathrm{SO}_{4}$. 
pure levoglucosan. It should be pointed out that $\mathrm{NaCl}$ can react with $\mathrm{OH}$ to form $\mathrm{NaOH}$ and $\mathrm{Cl}$ (Laskin et al., 2003). Although this reaction may compete with that between levoglucosan and $\mathrm{OH}$, we still observed an increase in the rate constant, which means that the higher dispersion degree for levoglucosan in the mixtures than pure levoglucosan should be the main reason. For NaCl@levoglucosan and $\left(\mathrm{NH}_{4}\right)_{2} \mathrm{SO}_{4} @$ levoglucosan, the carbon contents (wt) on these two mixtures (7.97\% and 6.49\%) are much lower than that on levoglucosan@NaCl and levoglucosan@ $\left(\mathrm{NH}_{4}\right)_{2} \mathrm{SO}_{4}$, and just slightly higher than that on pure $\mathrm{NaCl}$ and $\left(\mathrm{NH}_{4}\right)_{2} \mathrm{SO}_{4}$. Consider levoglucosan have certain solubility in water, the surface of these samples ( $\mathrm{NaCl} @ l e v o g l u c o s a n$ and $\left(\mathrm{NH}_{4}\right)_{2} \mathrm{SO}_{4} @$ levoglucosan) may composed of small quantities of levoglucosan and large quantities of the inorganics. Therefore, the reduction of the rate constant should be ascribed to inhabitation of inorganic species to the levoglucosan$\mathrm{OH}$ reaction.

It is interesting to note that the levoglucosan-OH rate constant could be significantly reduced when levoglucosan was mixed with soot particles (corresponding to levoglucosan@soot). Owing to the difficulties of SEM-EDX analysis in detecting carbon-based materials, the accurate surface element composition for levoglucosan@soot cannot be detected. However, as the surface area of soot is relatively high $\left(97.24 \mathrm{~m}^{2} \mathrm{~g}^{-1}\right)$, levoglucosan may enter the inner channels of soot and prevent the surface contact between levoglucosan and $\mathrm{OH}$. On the other hand, it is also possible that soot is reactive toward $\mathrm{OH}$ (Fenimore and Jones, 1967), thus leading to the lower reactivity with $\mathrm{OH}$ for levoglucosan dispersed on soot. Hennigan et al. (2010) observed the difference of levoglucosan stability among pure levoglucosan, wood smoke extract and wood smoke. From their results, pure levoglucosan showed the highest reactivity, while wood smoke the lowest. However, the rate constant for their lowest case is still higher than that in our study with the mixed soot.

In the study of mixed samples, the low mass content of levoglucosan mixtures (equivalently $5.0 \mu \mathrm{g}$ for each sample) was used to keep a unified initial concentration of levoglucosan as for pure levoglucosan studies, this may cause complete or partial dissolution of levoglucosan. Therefore, three mixed samples including levoglucosan@soot, NaCl@levoglucosan and levoglucosan@( $\left.\mathrm{NH}_{4}\right)_{2} \mathrm{SO}_{4}$ with high content of levoglucosan (wt \%) (approximately 5\%) were chosen and further investigated to avoid complete dissolution of levoglucosan. The results were shown in Fig. S7. It can be seen that the content of levoglucosan does not obviously affect the degradation rate of levoglucosan. Furthermore, in ambient particles, it is impossible that levoglucosan exists in a pure particle. The measured concentration of levoglucosan is very low $\left(14.4-430 \mathrm{ng} \mathrm{m}^{-3}\right.$ ) (Leithead et al., 2006; Xie et al., 2010). Therefore, the low concentration of levoglucosan prepared in this study should be more representative to simulate the ambient case.

\section{Conclusions and atmospheric implications}

In this study, the kinetics of levoglucosan degradation by hydroxyl radicals were measured using a flow reactor under different environmental conditions including temperature, $\mathrm{RH}$, and mixing states, to understand the atmospheric stability of levoglucosan. A prominent degradation of levoglucosan was observed and relative humidity, temperature and the mixing state can significantly influence the degradation rate.

The results showed the second-order rate constant $\left(k_{2}\right)$ for the reaction of pure levoglucosan with $\mathrm{OH}$ is $(9.17 \pm 1.16) \times 10^{-12} \mathrm{~cm}^{3}$ molecules ${ }^{-1} \mathrm{~s}^{-1}$ at $25^{\circ} \mathrm{C}$ and $40 \% \mathrm{RH}$, thus it is necessary to correct the measured concentration of levoglucosan in source apportionment due to air mass aging. On the other hand, environmental factors such as RH and temperature also likely play important roles in the atmospheric stability of levoglucosan. At $25^{\circ} \mathrm{C}$, the secondorder rate constant $\left(k_{2}\right)$ of pure levoglucosan linearly decreases with increasing $\mathrm{RH}\left(k_{2}=(1.50 \pm 0.04) \times 10^{-11}\right.$ $\left.-(1.31 \pm 0.11) \times 10^{-11} R H\right)$; while it increases with increasing temperature and follows the Arrhenius equation $k_{2}=(6.2 \pm 5.6) \times 10^{-9} \exp [(-1922.5 \pm 268.2) / T]$ when the $\mathrm{RH}$ is $40 \%$. Higher relative humidity and lower temperature can lead to longer lifetimes of levoglucosan. Moreover, the mixing state with inorganic salts and soot cannot be ignored: levoglucosan coated on $\left(\mathrm{NH}_{4}\right)_{2} \mathrm{SO}_{4}$ or $\mathrm{NaCl}$ shows larger rate constants to $\mathrm{OH}$, whereas levoglucosan coated on soot shows smaller rate constants compared with pure levoglucosan; either $\left(\mathrm{NH}_{4}\right)_{2} \mathrm{SO}_{4}$ or $\mathrm{NaCl}$ internally mixed with levoglucosan (corresponding to $\left(\mathrm{NH}_{4}\right)_{2} \mathrm{SO}_{4} @$ levoglucosan and $\mathrm{NaCl} @$ levoglucosan) prominently inhibits the degradation of levoglucosan. Furthermore, when mixed with such inorganics, different levoglucosan content will not significantly influence its decay rate.

$\mathrm{OH}, \mathrm{NO}_{3}, \mathrm{Cl}$ radical and $\mathrm{O}_{3}$ are the main effective oxidants in the atmosphere, and $\mathrm{OH}$ radical usually plays the dominant role (Atkinson, 1988; Kwok and Atkinson, 1995). Therefore, the rate constants determined in this study can be used to calculate the atmospheric lifetimes of levoglucosan with respect to the reaction with $\mathrm{OH}$ radicals. The atmospheric lifetime of levoglucosan $(\tau)$ was calculated according to the following equation:

$$
\tau=\frac{1}{k_{2}[\mathrm{OH}]}
$$

Assuming the typical concentration for the $12 \mathrm{~h}$ average value of $\mathrm{OH}$ to be $1.5 \times 10^{6}$ molecules $\mathrm{cm}^{-3}$, the atmospheric lifetime for pure levoglucosan is $1.7 \pm 0.2$ days. The lifetime calculated in this study is comparable to those in the literature (Hennigan et al., 2010), indicating levoglucosan may not stable enough in the atmosphere. The atmospheric lifetime of levoglucosan under different environmental conditions is listed in Table 1. It varies from 1.2 to 3.9 days under different environmental conditions and different mixing states, indicating that the environmental conditions and mixing states have prominent impacts on the degradation kinetics and lifetime of levoglucosan. In particular, soot may have the most prominent effect on the degradation kinetics of levoglucosan.

Some previous studies have pointed out that the influence of air mass aging on the concentration of levoglucosan is noteworthy when carrying out source apportionment based on the chemical mass balance method, but some other researchers considered levoglucosan still to be an ideal tracer for biomass burning due to its high emission factors and relatively high concentrations (Hoffmann et al., 2010). Recent studies related to the lifetime of levoglucosan were investigated to be $0.7-2.2$ days by Hennigan et al. using a smog chamber (Hennigan et al., 2010) and 0.5-3.4 days by Hoffmann et al. (2010) using the SPACCIM model. Our research point out a wide range of levoglucosan lifetimes under different environmental conditions, and shows the longest one when mixed with soot particles.

It should be pointed out that the longest lifetime of levoglucosan measured in this study is still shorter than the residence time of aerosols in the troposphere. This means the concentration of levoglucosan measured in field measurements for source apportionment should be underestimated greatly, thus introducing a significant error in source apportionment. As for other type of tracers, such as $n$-alkanes, hopanes and steranes, Lambe et al. (2009) also pointed out that neglecting degradation of these tracers by $\mathrm{OH}$ should lead to a significant error for source apportionment. Therefore, understanding about the fate of these tracers in the atmosphere should be updated to ensure more effective results in source apportionment. 


\section{Acknowledgements}

This research was funded by the National Natural Science Foundation of China (21190054) and the Strategic Priority Research Program of the Chinese Academy of Sciences (XDB05010300).

\section{Appendix A. Supplementary data}

Supplementary data related to this article can be found at http:// dx.doi.org/10.1016/j.atmosenv.2014.03.054.

\section{References}

Atkinson, R., 1988. Estimation of gas-phase hydroxyl radical rate constants for organic chemicals. Environmental Toxicology and Chemistry 7, 435-442.

Badger, C.L., Griffiths, P.T., George, I., Abbatt, J.P., Cox, R.A., 2006. Reactive uptake of $\mathrm{N}_{2} \mathrm{O}_{5}$ by aerosol particles containing mixtures of humic acid and ammonium sulfate. The Journal of Physical Chemistry A 110, 6986-6994.

Bai, J., Sun, X., Zhang, C., Xu, Y., Qi, C., 2013. The OH-initiated atmospheric reaction mechanism and kinetics for levoglucosan emitted in biomass burning. Chemosphere 93, 2004-2010.

Chiueh, C.C., Krishna, G., Tulsi, P., Obata, T., Lang, K., Huang, S.-J., Murphy, D.L., 1992 Intracranial microdialysis of salicylic acid to detect hydroxyl radical generation through dopamine autooxidation in the caudate nucleus: effects of MPP+. Free Radical Biology and Medicine 13, 581-583.

Chow, J.C., Watson, J.G., 2002. Review of $\mathrm{PM}_{2.5}$ and $\mathrm{PM}_{10}$ apportionment for fossil fuel combustion and other sources by the chemical mass balance receptor model. Energy \& Fuels 16, 222-260.

Ding, X., Wang, X.-M., Zheng, M., 2011. The influence of temperature and aeroso acidity on biogenic secondary organic aerosol tracers: observations at a rural site in the central Pearl River Delta region, South China. Atmospheric Environment 45, 1303-1311.

Engling, G., Carrico, C.M., Kreldenweis, S.M., Collett, J.L., Day, D.E., Malm, W.C., Lincoln, E., Hao, W.M., Iinuma, Y., Herrmann, H., 2006. Determination of levoglucosan in biomass combustion aerosol by high-performance anion-exchange chromatography with pulsed amperometric detection. Atmospheric Environment 40, S299-S311.

Fenimore, C.P., Jones, G.W., 1967. Oxidation of soot by hydroxyl radicals. Journal of Physical Chemistry 71, 593-597.

George, I.J., Abbatt, J.P., 2010. Heterogeneous oxidation of atmospheric aerosol particles by gas-phase radicals. Nature Chemistry 2, 713-722.

Healy, R.M., Hellebust, S., Kourtchev, I., Allanic, A., O'Connor, I.P., Bell, J.M. Healy, D.A., Sodeau, J.R., Wenger, J.C., 2010. Source apportionment of $\mathrm{PM}_{2.5}$ in Cork Harbour, Ireland using a combination of single particle mass spectrometry and quantitative semi-continuous measurements. Atmospheric Chemistry and Physics 10, 9593-9613.

Hennigan, C.J., Sullivan, A.P., Collett, J.L., Robinson, A.L., 2010. Levoglucosan stability in biomass burning particles exposed to hydroxyl radicals. Geophysical Research Letters 37, L09806.

Hoffmann, D., Tilgner, A., Iinuma, Y., Herrmann, H., 2010. Atmospheric stability of levoglucosan - a detailed laboratory and modeling study. Environmental Science \& Technology 44, 694-699.

Iuga, C., Galano, A., Alvarez-Idaboy, R., Sainz-Dìaz, I., Uc, V.H., Vivier-Bunge, A., 2012. InTech-reactivity trends in radical molecule tropospheric reactions - a quantum chemistry and computational kinetics approach. In: Yucel, Ismail (Ed.), Atmospheric Model Applications.

Kessler, S.H., Smith, J.D., Che, D.L., Worsnop, D.R., Wilson, K.R., Kroll, J.H., 2010 Chemical sinks of organic aerosol: kinetics and products of the heterogeneous oxidation of erythritol and levoglucosan. Environmental Science \& Technology 44, 7005-7010.

Keyser, L.F., Moore, S.B., Leu, M.T., 1991. Surface reaction and pore diffusion in flowtube reactors. Journal of Physical Chemistry 95, 5496-5502.

Kozinski, J.A., Saade, R., 1998. Effect of biomass burning on the formation of soot particles and heavy hydrocarbons. An experimental study. Fuel 77, 225-237.

Kwok, E.S.C., Atkinson, R., 1995. Estimation of hydroxyl radical reaction-rate constants for gas-phase organic-compounds using a structure-reactivity relationship - an update. Atmospheric Environment 29, 1685-1695.

Lambe, A.T., Miracolo, M.A., Hennigan, C.J., Robinson, A.L., Donahue, N.M., 2009 Effective rate constants and uptake coefficients for the reactions of organic molecular markers (n-alkanes, hopanes, and steranes) in motor oil and diese primary organic aerosols with hydroxyl radicals. Environmental Science \& Technology 43, 8794-8800.

Lanz, V.A., Alfarra, M.R., Baltensperger, U., Buchmann, B., Hueglin, C., Prevot, A.S.H 2007. Source apportionment of submicron organic aerosols at an urban site by factor analytical modelling of aerosol mass spectra. Atmospheric Chemistry and Physics 7, 1503-1522.
Laskin, A., Gaspar, D.J., Wang, W., Hunt, S.W., Cowin, J.P., Colson, S.D., FinlaysonPitts, B.J., 2003. Reactions at interfaces as a source of sulfate formation in seasalt particles. Science 301, 340-344.

Lee, W., Stevens, P.S., Hites, R.A., 2003. Rate constants for the gas-phase reactions of methylphenanthrenes with $\mathrm{OH}$ as a function of temperature. Journal of Physical Chemistry A 107, 6603-6608.

Leithead, A., Li, S.-M., Hoff, R., Cheng, Y., Brook, J., 2006. Levoglucosan and dehydroabietic acid: evidence of biomass burning impact on aerosols in the Lower Fraser Valley. Atmospheric Environment 40, 2721-2734.

Lin, L., Lee, M.L., Eatough, D.J., 2010. Review of recent advances in detection of organic markers in fine particulate matter and their use for source apportionment. Journal of the Air \& Waste Management Association 60, 3-25.

Ma, J., Liu, Y., He, H., 2010a. Degradation kinetics of anthracene by ozone on mineral oxides. Atmospheric Environment 44, 4446-4453.

Ma, Q., Liu, Y., He, H., 2010b. The utilization of physisorption analyzer for studying the hygroscopic properties of atmospheric relevant particles. The Journal of Physical Chemistry A 114, 4232-4237.

May, A.A., Saleh, R., Hennigan, C.J., Donahue, N.M., Robinson, A.L., 2012. Volatility of organic molecular markers used for source apportionment analysis: measurements and implications for atmospheric lifetime. Environmental Science \& Technology 46, 12435-12444.

Meylan, W.M., Howard, P.H., 1993. Computer estimation of the atmospheric gasphase reaction rate of organic compounds with hydroxyl radicals and ozone. Chemosphere 26, 2293-2299.

Mochida, M., Kawamura, K., Fu, P., Takemura, T., 2010. Seasonal variation of levoglucosan in aerosols over the western North Pacific and its assessment as a biomass-burning tracer. Atmospheric Environment 44, 3511-3518.

Perry, R.A., Atkinson, R., Pitts, J.N., 1977. Kinetics and mechanism of the gas phase reaction of hydroxyl radicals with aromatic hydrocarbons over the temperature range 296-473 K. The Journal of Physical Chemistry 81, 296-304.

Pietrogrande, M.C., Bacco, D., Mercuriali, M., 2010. GC-MS analysis of lowmolecular-weight dicarboxylic acids in atmospheric aerosol: comparison between silylation and esterification derivatization procedures. Analytical and Bioanalytical Chemistry 396, 877-885.

Saarnio, K., Teinila, K., Aurela, M., Timonen, H., Hillamo, R., 2010. High-performance anion-exchange chromatography-mass spectrometry method for determination of levoglucosan, mannosan, and galactosan in atmospheric fine particulate matter. Analytical and Bioanalytical Chemistry 398, 2253-2264.

Schauer, J.J., Rogge, W.F., Hildemann, L.M., Mazurek, M.A., Cass, G.R., Simoneit, B.R.T., 1996. Source apportionment of airborne particulate matter using organic compounds as tracers. Atmospheric Environment 30, 3837-3855.

Shiraiwa, M., Poschl, U., Knopf, D.A., 2012. Multiphase chemical kinetics of $\mathrm{NO}_{3}$ radicals reacting with organic aerosol components from biomass burning. Environmental Science \& Technology 46, 6630-6636.

Shiraiwa, M., Sosedova, Y., Rouviere, A., Yang, H., Zhang, Y., Abbatt, J.P., Ammann, M., Poschl, U., 2011. The role of long-lived reactive oxygen intermediates in the reaction of ozone with aerosol particles. Nature chemistry 3, 291-295.

Simoneit, B.R.T., Elias, V.O., 2001. Detecting organic tracers from biomass burning in the atmosphere. Marine Pollution Bulletin 42, 805-810.

Slade, J.H., Knopf, D.A., 2013. Heterogeneous OH oxidation of biomass burning organic aerosol surrogate compounds: assessment of volatilisation products and the role of $\mathrm{OH}$ concentration on the reactive uptake kinetics. Physical Chemistry Chemical Physics 15, 5898-5915.

Stone, E., Schauer, J., Quraishi, T.A., Mahmood, A., 2010. Chemical characterization and source apportionment of fine and coarse particulate matter in Lahore, Pakistan. Atmospheric Environment 44, 1062-1070.

Stone, E.A., Snyder, D.C., Sheesley, R.J., Sullivan, A.P., Weber, R.J., Schauer, J.J., 2008. Source apportionment of fine organic aerosol in Mexico City during the MILAGRO experiment 2006. Atmospheric Chemistry and Physics 8, 1249-1259.

Underwood, G.M., Li, P., Al-Abadleh, H., Grassian, V.H., 2001. A Knudsen cell study of the heterogeneous reactivity of nitric acid on oxide and mineral dust particles. Journal of Physical Chemistry A 105, 6609-6620.

Vermote, E., Ellicott, E., Dubovik, O., Lapyonok, T., Chin, M., Giglio, L., Roberts, G.J., 2009. An approach to estimate global biomass burning emissions of organic and black carbon from MODIS fire radiative power. Journal of Geophysical Research 114, D18205.

Weis, D.D., Ewing, G.E., 1999. Water content and morphology of sodium chloride aerosol particles. Journal of Geophysical Research 104, 21275-21285.

Widmann, J.F. Davis, E.J. 1997. Mathematical models of the uptake of $\mathrm{ClONO}_{2}$ and other gases by atmospheric aerosols. Journal of Aerosol Science 28, 87-106.

Xie, M., Wang, G., Hu, S., Gao, S., Han, Q., Xu, Y., Feng, J., 2010. Polar organic and inorganic markers in $\mathrm{PM}_{10}$ aerosols from an inland city of China - seasonal trends and sources. Science of the Total Environment 408, 5452-5460.

Yttri, K.E., Dye, C., Braathen, O.A., Simpson, D., Steinnes, E., 2009. Carbonaceous aerosols in Norwegian urban areas. Atmospheric Chemistry and Physics 9 , 2007-2020.

Zhou, S., Lee, A.K.Y., McWhinney, R.D., Abbatt, J.P.D., 2012. Burial effects of organic coatings on the heterogeneous reactivity of particle-borne benzo[a]pyrene (BaP) toward ozone. The Journal of Physical Chemistry A 116, 7050-7056. 